\title{
PENGARUH JENIS PUPUK GROWMORE DAN BENZILADENIN TERHADAP PERTUMBUHAN DAN PEMBUNGAAN ANGGREK Dendrobium
}

\author{
Pitriyanto, Dwi Hapsoro \& Yusnita \\ Jurusan Budidaya Pertanian, Fakultas Pertanian Universitas Lampung \\ Jl. Soemantri brojonegoro No. 1 Bandar Lampung 35145 \\ E-mail:ynto.hrt@gmail.com
}

\begin{abstract}
ABSTRAK
Untuk pertumbuhan vegetatif, tanaman membutuhkan pupuk dengan kandungan nitrogen $(\mathrm{N})$ yang tinggi, sedangkan untuk masuk ke fase generatif tanaman membutuhkan pupuk dengan kandungan fosfor $(\mathrm{P})$ dan kalium $(\mathrm{K})$ yang tinggi. Pemberian ZPT benziladenin dilaporkan dapat merangsang pertumbuhan anggrek Phalaenopsis dan Dendrobium pada waktu aklimatisasi. Disamping itu, pemberian BA juga dilaporkan dapat merangsang pembungaan pada anggrek Doritaenopsis dan Phalaenopsis. Penelitian ini bertujuan (1) mengetahui pengaruh jenis pupuk Growmore terhadap pertumbuhan dan pembungaan anggrek Dendrobium, (2) mengetahui pengaruh benziladenin terhadap pertumbuhan dan pembungaan anggrek Dendrobium, dan (3) mengetahui apakah ada interaksi antara jenis pupuk dan benziladenin dalam mempengaruhi pertumbuhan dan pembungaan anggrek Dendrobium. Penelitian bertempat di rumah kaca Fakultas Pertanian Universitas Lampung, dan dilaksanakan selama 4 bulan, yaitu dari bulan Februari sampai dengan bulan Juli 2011. Perlakuan disusun secara faktorial (3x2) dalam rancangan kelompok teracak sempurna (RKTS) dengan 3 ulangan. Faktor pertama adalah pupuk daun, yaitu pupuk GrowmoreBiru $\left(\mathrm{G}_{1}\right)$, GrowmoreMerah $\left(\mathrm{G}_{2}\right)$, GrowmoreBiru + GrowmoreMerah $\left(\mathrm{G}_{3}\right)$ dengan kosentrasi pupuk masing-masing adalah $2 \mathrm{~g} \mathrm{l}^{-1}$. Faktor kedua adalah benziladenin $(\mathrm{BA})$, yaitu tanpa pemberian $\mathrm{BA}\left(\mathrm{B}_{0}\right)$, dan pemberian $\mathrm{BA}\left(\mathrm{B}_{1}\right)$, dengan kosentrasi50 $\mathrm{mg}^{\mathrm{l}^{-1}}$. Setiap satuan percobaan terdiri dari 6 pot tanaman. Kesamaan ragam antar-perlakuan diuji dengan uji Bartlett. Kemudian data diolah dengan menggunakan sidik ragam yang dilanjutkan dengan uji BNT pada taraf nyata $5 \%$.Hasil analisis ragam menunjukkan bahwa pemberian GrowmoreBiru, GrowmoreMerah dan GrowmoreBiru + GrowmoreMerah tidak berpengaruh nyata terhadap tinggi tunas baru, jumlah tunas baru, jumlah akar primer, jumlah bunga, panjang malai, dan jumlah kuntum bunga. Pemberian BA dengan konsentrasi $50 \mathrm{mg} \mathrm{l}^{-1}$ tidak berpengaruh nyata terhadap tinggi tunas baru, jumlah tunas baru, jumlah akar primer, jumlah bunga, panjang malai dan jumlah kuntum bunga. Tidak ada pengaruh interaksi yang nyata antara pemberian pupuk dan pemberian ZPT terhadap seluruh variabel yang diamati yaitu tinggi tunas baru, jumlah tunas baru, jumlah akar primer, jumlah daun, panjang malai, dan jumlah kuntum bunga.
\end{abstract}

Kata kunci : benziladenin, growmore, pembungaan

\section{PENDAHULUAN}

Anggrek merupakan tanaman hias yang mempunyai nilai estetika tinggi.Bentuk dan warna bunganya yang unik menjadi daya tarik tersendiri sehingga banyak diminati orang (Widiastoety dkk, 2010). Tingginya minat akan bunga anggrek dapat ditunjukkan dengan peningkatan produksi anggrek dari tahun ke tahun. Data dari Badan Pusat Statistik (BPS) menunjukkan bahwa produksi bunga anggrek pada tahun 2007, 2008, 2009, 2010, dan 2011 berturut-turut (dalam juta tangkai) adalah 9,$5 ; 15,4 ; 16,2 ; 14,1$; dan 15,5. Sedangkan lima provinsi penghasil bunga anggrek terbesar adalah Jawa Barat (4,1 juta tangkai), Jawa Tengah (3,7 juta tangkai), Banten (2 juta tangkai), DKI Jakarta (1,7 juta tangkai), dan Bali (1,4 juta tangkai) (BPS, 2011).
Untuk pertumbuhan vegetatif, tanaman membutuhkan pupuk dengan kandungan nitrogen $(\mathrm{N})$ yang tinggi, sedangkan untuk masuk ke fase generatif tanaman membutuhkan pupuk dengan kandungan fosfor (P) dan kalium (K) yang tinggi (Hendaryono, 1998). Fosfor dibutuhkan tanaman untuk merangsang pertumbuhan akar, khususnya akar benih dan tanaman yang masih muda, untuk proses asimilasi, mempercepat pembungaan, dan untuk proses pembentukan biji (Lingga, 1999). Tanaman sebagian besar menyerap unsur hara fosfor dalam bentuk ion ortofosfat primer (H2PO4). Sejumlah kecil diserap dalam bentuk ion ortofosfat sekunder (HPO4) (Winarso, 2005).

Pemberian ZPT benziladenin dilaporkan dapat merangsang pertumbuhan anggrek Phalaenopsis (Handayani, 2011) dan Dendrobium (Suhar, 2012) pada wakktu aklimatisasi. Disamping itu, pemberian BA juga 
dilaporkan dapat merangsang pembungaan pada anggrek Doritaenopsis dan Phalaenopsis (Blanchard dan Runkle, 2008, Wu dan Chang, 2009).

Penelitian ini bertujuan untuk mengetahui: (1) pengaruh jenis pupuk Growmore terhadap pertumbuhan dan pembungaan anggrek Dendrobium, (2) pengaruh benziladenin terhadap pertumbuhan dan pembungaan anggrek Dendrobium, dan (3) apakah ada interaksi antara jenis pupuk dan benziladenin dalam mempengaruhi pertumbuhan dan pembungaan anggrek Dendrobium.

\section{BAHAN DAN METODE}

Penelitian bertempat di rumah kaca Fakultas Pertanian Universitas Lampung, dan dilaksanakan selama 4 bulan, yaitu dari bulan Februari sampai dengan bulan Juli 2011.

Bahan tanam yang digunakan dalam penelitian ini adalah bibit anggrek Dendrobium yang sudah berumur 17 bulan sejak aklimatisasi.Anggrek ini didapatkan dari penelitian sebelumnya (Alicia, 2011). Bahan tanaman anggrek memiliki rata-rata jumlah tunas lama 3-4 tunas pada tiap tanaman, dan memiliki tinggi rata-rata tiap tanaman sekitar 10-15 cm dari permukaan media, dengan rata-rata jumlah daun tiap tunas sekitar 4-5 daun.

Media tanam yang digunakan merupakan campuran antara pakis dan arang dengan perbandingan volume 2:1.Media diletakkan dalam pot plastik dengan ukuran diameter $20 \mathrm{~cm}$ dan tinggi $13 \mathrm{~cm}$. Sebelum campuran media tersebut dimasukkan ke dalam pot, di bagian dasar pot diletakkan sterofom $(2 \times 2 \mathrm{~cm})$ sampai volume $20 \%$ dari volume pot.Pakis dimasukkan ke dalam pot sampai volume $70 \%$ dari volume pot, lalu dimasukkan arang kayu sampai volume $95 \%$ dari volume pot.

Sebelum digunakan, pakis direndam dalam bak plastik yang berisi $2 \mathrm{~g}^{-1}$ Dithane M-45 selama 24 jam. Selanjutnya pakis ditiriskan dan dikeringkan selama 2 hari kemudian dicincang halus berukuran panjang $2 \mathrm{~cm}$ lalu dimasukkan ke dalam pot.

Pupuk yang digunakan dalam penelitian ini adalah GrowmoreBiru (32:10:10) dan GrowmoreMerah (10:55:10). Kedua pupuk tersebut masing-maisng dilarutkan dalam air dengan konsentrasi $2 \mathrm{~g}^{-1}$. Sebanyak 2 gr pupuk Growmore dilarutkan dengan air sebanyak 1 liter, lalu diaduk hingga merata, kemudian pupuk daun Growmore disemprotkan pada daun anggrek secara merata sebanyak $15 \mathrm{ml}$ atau 10 kali semprot.Aplikasi BA dilakukan selama dua bulan, dengan dosis $50 \mathrm{mg} \mathrm{l}^{-1}$. penyemprotan BA sama dalam satu bulan dilakukan 2 kali penyemprotan, dan untuk dua bulan 4 kali.
Penyemprotan pada permukaan daun sebanyak $15 \mathrm{ml}$ atau 10 kali semprotan.

Proses pembuatan larutan BA, yaitu dengan menimbang $50 \mathrm{mg}$ BA, kemudian meletakkan BA tersebut di sudut gelas beaker ukuran $20 \mathrm{ml}$, diteteskan $3 \mathrm{ml} \mathrm{HCl}$ pada BA tersebut, lalu diaduk hingga BA tercampur dengan $\mathrm{HCl}$. Setelah $\mathrm{BA}$ larut dalam $\mathrm{HCl}$, dimasukkan aquades sedikit demi sedikit, sampai larutan menjadi bening, setelah itu ditera menggunakan gelas ukur sampai volume satu liter.

Perlakuan disusun secara faktorial $(3 \times 2)$ dalam rancangan kelompok teracak sempurna (RKTS) dengan 3 ulangan. Faktor pertama adalah pupuk daun, yaitu pupuk GrowmoreBiru $\left(\mathrm{G}_{1}\right)$, GrowmoreMerah $\left(\mathrm{G}_{2}\right)$, GrowmoreBiru + GrowmoreMerah $\left(\mathrm{G}_{3}\right)$ dengan kosentrasi pupuk masing-masing adalah $2 \mathrm{~g} \mathrm{l}^{-1}$. Faktor kedua adalah benziladenin (BA), yaitu tanpa pemberian BA $\left(B_{0}\right)$, dan pemberian BA $\left(B_{1}\right)$, dengan kosentrasi50 mg $1^{-1}$. Setiap satuan percobaan terdiri dari 6 pot tanaman.Kesamaan ragam antarperlakuandiuji dengan uji Bartlett. Kemudian data diolah dengan menggunakan sidik ragam yang dilanjutkan dengan uji BNT pada $\alpha=$ 0,05 .

Perlakuan diterapkan 3 minggu setelahrepotting. Pemberian pupuk daun dilakukan seminggu sekali selama 4 bulan dengan masing-masing kosentrasi $2 \mathrm{~g} \mathrm{l}^{-1}$. Untuk aplikasi BA, pemberian BA dilakukan 2 kali dalam satu bulan dan dilaksanakan selama 4 bulan. Cara aplikasi pupuk Growmore dengan penyemprotan menggunakan sprayer pada bagian seluruh daun, begitu juga aplikasi BA menggunakan sprayer dan disemprotkan keseluruh bagian daun.

Untuk pupuk daun Growmore penyemprotan dilakukan sebanyak $15 \mathrm{ml}$ atau 10 kali semprot. Untuk BA jumlah volume semprot sama dengan pupuk daun, yaitu $10 \mathrm{ml}$. Volume semprot ini diperoleh melalui ratarata 3 tanaman yang disemprot, lalu volume air yang keluar dari sprayer dihitung.

Penyiraman tanaman anggrek dilakukan setiap hari yaitu pada pagi atau sore hari dan pengendalian hama penyakit tanaman dengan melakukan penyemprotan seminggu sekali dengan menggunakan fungisida (Dithane M-45) untuk mengendalikan serangan jamur dan insektisida (Curacron) untuk mengendalikan serangan hama serangga.

Variabel pengamatan dalam penelitian ini adalah (1) Jumlah tunas, yaitu dengan menghitung jumlah tunas yang muncul dengan tinggi minimal $0,5 \mathrm{~cm}$. (2) Tinggi tunas, diukur dari pangkal batang tunas sampai titik tumbuh tertinggi. (3) Waktu munculnya bunga (dalam satuan hari), diamati setiap hari setelah perlakuan sampai munculnya bunga. (4) Jumlah bunga dihitung untuk 
seluruh bunga yang muncul dalam satu tanaman. (5) Jumlah kuntum bunga, yaitu dengan menghitung seluruh kuntum bunga dalam satu tanaman. (6) Jumlah akar primer, yaitu dihitung jumlah seluruh akar yang muncul pada pangkal batang dan akar diamati pada akhir penelitian.

\section{HASIL DAN PEMBAHASAN}

Pengamatan terhadap seedling anggrek Dendrobium hibrida yang diberi perlakuan Growmore danzat pengatur tumbuh (ZPT)benziladenin (BA) menunjukkan bahwa perlakuan tidak berpengaruh nyata terhadap pertumbuhan (Tabel 1 dan 2). Hasil analisis ragam menunjukkan bahwa pemberian Growmore Biru, Growmore Merah dan Growmore Biru + Growmore Merah tidak berpengaruh nyata terhadap tinggi tunas baru, jumlah tunas baru, jumlah akar primer, jumlah kuntum bunga, panjang malai, dan jumlah bunga.
Pemberian BA dengan konsentrasi $50 \mathrm{mg} \mathrm{l}^{-1}$ tidak berpengaruh nyata terhadap tinggi tunas baru, jumlah tunas baru, jumlah akar primer dan jumlah bunga (Tabel 1 dan 2). Tidak ada pengaruh interaksi yang nyata antara pemberian pupuk dan pemberian ZPT terhadap seluruh variabel yang diamati yaitu tinggi tunas baru, jumlah tunas baru, dan jumlah akar primer.

Meskipun secara statistik tidak berpengaruh, dari data pada Tabel 2 tampak bahwa tanpa BA dari 54 tanaman hanya 2 tanaman yang berbunga, sedangkan dengan BA ada 5 tanaman yang berbunga. Seandainya pengamatan tidak terhenti pada saat tanaman berumur 4 bulan, tetapi dilanjutkan pada bulan-bulan berikutnya, mungkin pengaruh BA akan terlihat. Dengan perkataan lain, bahan tanaman yang diperlakukan mungkin masih terlalu muda. Praktek budidaya anggrek menunjukkan bahwa tanaman anggrek Dendrobium mulai berbunga pada umur 2 tahun (Hee et al., 2007 dalam Nambiar et al., 2012). Pada penelitian ini, anggrek yang perlakukan

Tabel 1. Pengaruh konsentrasi benziladenin dan pupuk Growmore terhadap jumlah tunas, panjang tunas dan jumlah akar primer anggrek Dendrobium, empat bulan setelah penelitian

\begin{tabular}{|c|c|c|c|c|}
\hline & Perlakuan & Jumlah tunas & Panjang tunas $(\mathrm{cm})$ & Jumlah akar \\
\hline \multirow{3}{*}{ Tanpa BA } & GrowmoreBiru & 1,1 & 25,4 & 6,9 \\
\hline & GrowmoreMerah & 1,1 & 27,6 & 6,3 \\
\hline & $\begin{array}{l}\text { GrowmoreBiru + } \\
\text { GrowmoreMerah }\end{array}$ & 1,1 & 25,1 & 6,3 \\
\hline \multirow{3}{*}{$\begin{array}{c}\text { Dengan } \\
\text { BA }\end{array}$} & GrowmoreBiru & 1,1 & 24,7 & 6,7 \\
\hline & GrowmoreMerah & 1,1 & 26,8 & 6,2 \\
\hline & $\begin{array}{l}\text { GrowmoreBiru + } \\
\text { GrowmoreMerah }\end{array}$ & 1,3 & 24,4 & 6,7 \\
\hline
\end{tabular}

Tabel 2. Pengaruh konsentrasi benziladenin dan pupuk Growmore terhadap jumlah bunga, jumlah kuntum bunga, dan panjang malai anggrek Dendrobium,empat bulan setelan penelitian

\begin{tabular}{clccc}
\hline & Perlakuan & Jumlah bunga & $\begin{array}{c}\text { Jumlah kuntum } \\
\text { bunga }\end{array}$ & $\begin{array}{c}\text { Panjang malai bunga } \\
(\mathrm{cm})\end{array}$ \\
\hline \multirow{2}{*}{ Tanpa BA } & GrowmoreBiru & 0 & 0 & 0 \\
& GrowmoreMerah & 1 & 4 & 25 \\
& GrowmoreBiru + & 1 & 8 & 33 \\
& GrowmoreMerah & & 4 & 19,3 \\
\hline Rata-rata & & 0,7 & 5,5 & 31,6 \\
BA & GrowmoreBiru & 2 & 4 & 27 \\
& GrowmoreMerah & 1 & 4,5 & \\
\hline Rata-rata & GrowmoreBiru + & 2 & & 24,6 \\
& GrowmoreMerah & & 4,7 & \\
\hline
\end{tabular}


baru berumur 17 bulan. Jadi pada waktu pengamatan dilakukan anggrek baru berumur 21 bulan (kurang dari 2 tahun).

\section{KESIMPULAN}

Berdasarkan hasil penelitian dapat disimpulkan bahwa jenis pupuk Growmore menghasilkan respon pertumbuhan yang tidak berbeda secara signifikan. Pemberian benziladenin tidak berpengaruh nyata terhadap pertumbuhan dan pembungaan. Tidak ada interaksi antara jenis pupuk dan pemberian benziladenin terhadap pertumbuhan dan pembungaan.

\section{DAFTAR PUSTAKA}

Alicia, J. 2011. Pengaruh Jenis Pupuk Daun dan Frekueni Pemberian Benziladenin terhadap Pembesaran Seedling Anggrek Dendrobium Hibrida. Skripsi. Universitas Lampung.

Blanchard, M. G. And E. S. Runkle. 2008. Benziladenine promotes flowering in Doritaenopsis and Phalaenopsis orchids. J. Plant Growth Regul. 27:141-151.

BPS. 2011. http://www.bps.go.id/menutab.php?tabel $=1 \&$ kat=3\&id_subyek=55. Diakses maret 2013 .

Handayani, Y. 2011. Persilangan Diallel lengkap dua Tetua Anggrek, Perkecambahan Biji dan Pembesaran Sedling in Vitro serta Aklimatisasi Phalaenopsis.Tesis. Program Magister Agronomi Universitas Lampung.
Hendaryono, D.S. 1998. Budidaya Anggrek Dengan Bibit dalam Botol. Yogyakarta. Kanisius.

Lingga, P. 1999. Petunjuk Penggunaan Pupuk. Penebar Swadaya. Jakarta.

Nambiar, N. Siang, C.T, dan Mahmood, M. 2012. Effect of 6-benzylaminopurine on flowering of a Dendrobium orchid.Australian Journal of Crop Science6(2):225-231.

Suhar. 2012. Respon Pertumbuhan Planlet Anggrek Dendrobium Hibrida pada Berbagai Konsentrasi Zat Pengatur Tumbuh selama Aklimatisasi. Skripsi. Jurusan Agroteknologi Fakultas Pertanian, Perikanan, dan Biologi. Universitas Bangka Belitung.

Widiastoety, D., N. Solvia, dan M, Soedarjo. 2010. Potensi anggrek Dendrobium dalam meningkatkan variasi dan kualitas anggrek bunga potong. Jurnal Litbang Pertanian.29 (3):101106.

Winarso, S. 2005. Kesuburan Tanah: Dasar Kesehatan dan Kualitas Tanah. Gava Media. Yogyakarta.

Wu, P. H and D. C. N. Chang. 2009. The use of N-Gbenziladenine to regulate flowering of phalaenopsis orchids. Hort Tech. 19(1):200-203. 